\title{
Considerações sobre a educação inclusiva e o tratamento do Outro
}

\author{
Considerations about inclusive education and the treatment of the Other
}

\author{
Michelle Hattori Fuziy ${ }^{[a]}$, Rosa Maria Marini Mariotto ${ }^{[b]}$
}

[a] Psicóloga psicanalista formada pela Universidade Estadual de Londrina (UEL), especialista em Psicologia Clínica pela Pontifícia Universidade Católica do Paraná (PUCPR), Londrina, PR - Brasil, e-mail: michellefuziy@yahoo.com.br

[b] Professora Doutora da Pontifícia Universidade Católica do Paraná (PUCPR), psicanalista membro da Associação Psicanalítica de Curitiba, Curitiba, PR - Brasil, e-mail: rosa.mariotto@pucpr.br

\section{Resumo}

Este artigo pretende refletir a respeito da educação inclusiva com crianças psicóticas e autistas, utilizando o referencial freudiano-lacaniano, a partir da reflexão sobre o "Programa Educação Inclusiva: direito à diversidade”. Criado pelo governo em 2003, o objetivo do projeto é a escolarização de alunos com necessidades educacionais especiais nas escolas e classes comuns da rede regular de ensino. Para que essas crianças se beneficiem do programa, são necessárias reformulações na escola para que, de fato, se possa incluir quem está excluído, questionando o ideário político-pedagógico - reformulações que exigem mudanças não apenas no espaço físico e nos conteúdos programáticos, mas um redimensionamento na preparação do professor, ou seja, mudanças referentes à organização e ajuste constante do agenciamento simbólico, com a finalidade de tornar possível uma ação do coletivo. Isto é, para que se possa realizar esse tratamento do Outro, toda a equipe, composta por diferentes áreas, deve ser parceira na construção clínica. Assim, a partir da proposta de Tratamento do Outro, busca-se explorar certas possibilidades, particularmente a de colocar no lugar outra Alteridade que seja alternativa ao Outro primordial do sujeito. Enfim, trata-se de questionar se essas crianças têm estrutura suficiente para usufruir daquilo que o convívio social pode proporcionar-lhes e se a escola reconhece a criança menos sob a ótica de suas capacidades cognitivas do que na sua condição de sujeito do desejo, possibilitando assim que elas se beneficiem das contribuições que o laço social proporciona, considerando-as como sujeitos do desejo, para que então seja possível ver o aluno em sua subjetividade.

Palavras-chave: Psicanálise. Educação inclusiva. Psicose. Autismo. Tratamento do Outro. 


\begin{abstract}
This article intends to reflect about inclusive education with psychotic and autistic children, utilizing the freudianlacanian referential, departing from the reflection on the "Inclusive Education Program: right to diversity". Created by the government in 2003, the program aims to educate students with special needs in the schools and common classes of the regular educational system. For these children to benefit from this program some reformulations in school are required, so that the ones excluded can be included, questioning the political-pedagogical system of ideas reformulations that demand changes not only in physical space and in program contents, but a redimensioning of teacher's preparation, that is changes regarding the organization and constant adjustment of symbolic agency with the aim to make possible a collective action. For this Treatment of the Other to be done, the whole group must be partner in building clinic. This way, based on the Treatment of the Other, it is tried to explore certain possibilities, particularly the one of putting another Alterity that is alternative to the primordial Other of the subject. Finally, it is questionable whether these children have enough structure to take advantage of what the social interaction can provide and whether the school, and if these children recognizes themselves least from the perspective of their cognitive skills than in their capacity as a subject of desire, making possible that they benefit from the contributions provided by the social chain, considering them as the subject of desire so that one can see its student on its subjectivity.
\end{abstract}

Keywords: Psychoanalysis. Inclusive education. Psychosis. Autism. Treatment of the Other.

\section{Introduçáo}

Em 2003 foi iniciado o "Programa Educação Inclusiva: direito à diversidade", cujo objetivo é implantar uma política de educação inclusiva nos municípios brasileiros. Esse programa consiste em escolarizar alunos com necessidades educacionais especiais nas escolas e classes comuns da rede regular de ensino e apoiar a formação de gestores e educadores para efetivar a transformação dos sistemas educacionais em sistemas educacionais inclusivos.

O programa baseia-se no princípio da garantia do direito dos alunos com necessidades educacionais especiais de acesso e permanência, com qualidade, nas escolas da rede regular de ensino. A Secretaria de Educação Especial (SEESP) publicou no site do MEC os Conceitos da Educação Especial - Censo Escolar 2005, em que os alunos com necessidades educacionais especiais são definidos como aqueles que

apresentam, durante o processo educacional, dificuldades acentuadas de aprendizagem que podem ser: não vinculadas a uma causa orgânica específica ou relacionadas a condições, disfunções, limitações ou deficiências, abrangendo dificuldades de comunicação e sinalização diferenciadas dos demais alunos, bem como altas habilidades/superdotação (Secretaria de Educação Especial, 2005).
Esse programa procura contemplar todas as crianças ao direito de acesso à educação - um avanço importante, uma vez que a escola, conforme Kupfer (2000, p. 36), atribui um lugar social para a criança moderna, dando-lhe identidade. É por isso que a palavra "criança" está indissoluvelmente ligada ao escolar. "A História sublinha então uma dimensão da infância que é dada pelo campo social, que a enquadra, lhe dá significação e interpretação. O campo social também define um tempo para essa infância, que é justamente o da escolarização obrigatória" (Kupfer, 2000, p. 35).

$\mathrm{O}$ ato de educar, parafraseando a autora, está "no cerne da emergência de um sujeito" (Kupfer, 2000, p. 35). É por meio desse ato que o Outro Educador se intromete na carne do infans e o transforma em ser de linguagem. As marcas do desejo do adulto na criança são inscritas pela via da educação. Assim, o ato educativo se refere a todo ato de um adulto dirigido a uma criança, filiando o aprendiz a uma tradição existencial e permitindo o reconhecimento no outro.

Porém, tratar a política de educação inclusiva como resposta à demanda educativa de normalizar os ditos anormais, mascarados com a denominação de "alunos com necessidades educacionais especiais", é correr o risco de transformá-la em instrumento de segregação, uma vez que, sob efeito do discurso universalizante, a forma de entrada da criança na escola é imposta sem levar em conta sua 
singularidade, tomando-a a partir de uma vertente deficitária em que a dimensão de sujeito é excluída. Isso pode acontecer justamente porque os direitos à cidadania não protegem a criança contra a exclusão, como também não é só porque a criança com necessidades educacionais especiais está na escola de ensino regular que estarão garantidas condições de convivência e inserção no laço social.

Souza, Angeli e Veras (2000), ao analisar nos últimos seis anos documentos e textos oficiais com o tema da inclusão social e escolar de pessoas surdas, apontam algumas perspectivas distintas em relação ao discurso oficial dos enunciados proferidos e editados pelo MEC. Um dos textos é um decreto presidencial de 20 de dezembro 1999, que dispõe sobre a Política Nacional para a Integração da Pessoa Portadora de Deficiência. De acordo com as autoras, as crianças que são contempladas nessa política que, no referido texto, tratam-se especificamente de crianças surdas - são tratadas como deficientes. E, ao definir um conjunto de pessoas como deficientes, em vez de reconhecê-las como diferentes, os formuladores do discurso as tomam como aquelas que têm um déficit em relação aos outros, criando, assim, uma perspectiva normatizante, que remete a um ideal psicopedagógico de adequar os meios aos fins educativos. Dessa forma, é a lógica da exclusão que apoia o trabalho da inclusão, na medida em que o ideal de normalidade e igualdade exclui, abstrai qualquer diferença.

Ora, se entendermos que todo sujeito se constitui em torno de um defeito primordial - a do objeto enquanto falta -, qualquer criança é de fato alguém com necessidades especiais.

As autoras apontam outra perspectiva que subsidia o reconhecimento da diferenças em vez da fala oficial sobre a inclusão:

Reconhecer diferenças não significa, como sugeriria uma leitura equivocada, construir um discurso justificador das (e resignado em face das) distinções sociais, incluindo as diferenças de classe. Reconhecer diferenças significa recusar o discurso da normalidade e as práticas de normalização, que pretendem salvaguardar a alegada pureza das identidades que ela parece englobar. Reconhecer as diferenças significa exigir políticas públicas que levem em conta os direitos dos segmentos sociais diferenciados, e recusar políticas públicas assistencialistas e práticas que, em nome da inclusão, negam direitos essenciais, como o direito dos surdos a uma língua própria (Souza et al., 2000, p. 93).

Enfim, não se pode negar que esse foi um dos grandes avanços na implementação das políticas públicas, mas, se não for bem elaborada, com précondições para que as crianças sejam atendidas e com acompanhamento das equipes, os efeitos podem ser desastrosos.

Ressalta-se também que, apesar da importância da educação para a criança, Freud, em Análise Terminável e Interminável ([1937] 2006), considera o educar, ao lado de governar e psicanalisar, uma profissão impossível, uma vez que as pulsões sexuais são ineducáveis. $\mathrm{O}$ autor aponta que há limites na ação educativa, pois se chega sempre a resultados insatisfatórios, afirmando que o instrumento de ação do educador não é tão onipotente quanto se supõe.

No caso de crianças autistas ou psicóticas, cuja posição é refratária às normas sociais e de rechaço ao Outro, parece ser o extremo deste "impossível de educar". Como então sustentar o trabalho da educação inclusiva, que é tensionado tanto pelo universal - o ideal "da escola para todos" -, quanto pelo singular, ou seja, a particularidade do caso a caso? Quando e como, ao inserir a criança na escola, pode-se encontrar tanto resultados terapêuticos quanto devastadores?

Porisso se fazem necessários uma discussão e um acompanhamento minucioso de cada caso com os professores e a equipe de saúde, tanto no que se refere às questões sobre o tratamento, quanto sobre a possibilidade ou não de escolarização dessas crianças. Kupfer e Petri (2000, p. 117) complementam: “toda inclusão de crianças psicóticas e autistas precisa ser cuidadosa e acompanhada, podendo não ser recomendada em alguns momentos mais problemáticos da vida de uma criança".

De acordo com as autoras, para que fosse criado um programa que tem como objetivo a inclusão, supõe-se que as crianças especiais existem porque há diferenças "naturais" entre elas. E que, se elas estão fora da escola, é porque há um preconceito social a respeito da diferença. Em outro artigo, Kupfer (1997, p. 53) afirma que a educação regular exclui os diferentes e que as práticas pedagógicas adotadas pelas escolas produzem essa nova categoria de crianças, excluídas do sistema regular de ensino. 
Elas se tornam fracassadas escolares a partir do modo como a escola aborda, ataca, nega e desqualifica o degrau, a diferença social, o desencontro de linguagens entre as crianças de extração pobre, de um lado, e a escola comprometida com outras extrações sociais, de outro.

Kupfer e Petri (2000,p. 111) afirmam ainda que a modernidade criou a criança especial, produzida no e pelo discurso social escolar. A linguagem possui o poder de criação, contornando um Real e passando a dizê-lo, nomeando-o, ou seja, "uma rotulação que cria o objeto nomeado". O discurso escolar tem seus pontos de referências identitários nesse contorno que o ajuda a definir esse não-escolar - tanto é que algumas escolas não aceitam a inclusão escolar com o argumento de que "se não podem aprender, o que farão na escola?"

Mesmo que esse argumento seja justificável, não é passível de concordância. Ainda seguindo seu raciocínio, as autoras citadas discutem a respeito de muitos casos de insucesso dessa empreitada, principalmente nos casos de crianças psicóticas e autistas.

É por isso que se buscam reformulações no espaço escolar para que realmente seja possível incluir quem está excluído, questionando o ideário político-pedagógico e, principalmente, considerando os diferentes estilos e ritmos de aprendizagem. Isto é, considerar que não apenas o trabalho seja inclusivo, mas que a lógica que sustenta esse oficio seja inclusiva. Essa lógica supõe incluir a instituição e a equipe na reflexão a respeito dos recursos pedagógicos e subjetivos de que se dispõe para atuar com as tais crianças excluídas, bem como exige o entendimento dolugar que a ordem simbólica e seus agentes ocupam (ou não) na vida delas, sendo capaz de reconhecer quando o convívio escolar é facilitador de laço social, e quando a inscrição de marcas tem efeito educativo.

\section{Existência e consistência do Outro na psicose e no autismo}

É no intervalo entre dois significantes que uma vida se inicia: aquele que se refere ao desejo dos pais e aquele próprio ao sujeito do desejo. Submetido ao Outro materno, o pequeno ser é capturado na existência enquanto objeto, e é nesta condição que estará sujeito à linguagem. Fazendo identificar o objeto com a coisa, a mãe investe no filho sua porção fálica - e, portanto faltante -, realizando assim a presença do objeto $a$ na fantasia materna.

Enquanto agente da alienação, o Outro materno evidencia sua vocação interpretativa, já que traduz seu gesto, atribuindo-lhe significação, isto é, antecipando um sujeito antes mesmo que nesta carne exista um, e submetendo-o ao seu saber. A mãe, com isso, recorta com suas palavras o corpo da criança e estes objetos que deste corte se extraem indicam de modo imediato e direto que a falta que se pretendia obturar na operação da maternidade é potencializada no exercício da maternagem. Como esclarece Mariotto (2007, p. 58), para que a relação de um a outro não se perca na violência imaginária, a existência do infans deve desde sempre estar condicionada a dois tipos de alienação: a imaginária que compõe sua primeira carteira de identidade subjetiva -, e a simbólica, que o introduz na cultura, dando-lhe status de significante. "O reconhecimento do Outro, como mais-além do semelhante, é condição para que o sujeito seja pelo outro reconhecido."

É isso que permite que a criança não sature, para a mãe, a falta em que se apoia seu desejo. Jacques-Alain Miller (1998) considera que a mãe só é suficientemente boa se não o é em demasia, se os cuidados que ela dispensa à criança não a desviam de desejar enquanto mulher. Que a mãe seja como um crocodilo, metaforiza Lacan (1954/1993), que abriga dentro de sua boca a criança que, na condição de significante da falta, a sacie, mas não-toda, salvaguardando-a de sucumbir ao gozo total do Outro.

Miller (1998) afirma ainda que a metáfora infantil do falo só é bem-sucedida ao falhar, se não fixa o sujeito à identificação fálica e se, ao contrário, lhe dá acesso à significação fálica na modalidade de castração simbólica, preservando o não-todo do desejo feminino, não recalcando na mãe seu ser mulher. Para ele é essencial que a criança divida o sujeito feminino entre mãe e mulher, amor e desejo, e que o Pai humanize o desejo da mãe, tomando a mulher como causa de seu desejo. Enfim, a metáfora paterna remete a uma divisão do desejo, fazendo com que o bebê não seja tudo para o sujeito materno, possibilitando, deste modo, que a criança deseje e que, assim, exista. Aragão e Ramirez (2004, p. 89-105) complementam:

É por meio da metáfora paterna e de seu mecanismo fundamental, o recalque originário, que a criança efetuará uma substituição significante, 
colocando um novo no lugar do significante originário do desejo da mãe. À medida que o significante originário é substituído pelo novo, automaticamente ele é recalcado, passando para o inconsciente, o que permite de fato à criança efetivar a renúncia ao objeto inaugural de desejo, tornando inconsciente o que antes o significava.

Desta forma, a operação de engendramento de um ser de linguagem requer como base fundamental de cálculo a presença do Outro primordial, tanto na sua vertente de agente de alienação quanto em sua capacidade de disjunção, deixando-se atravessar por um terceiro para além da díade narcísica. Mariotto (2007, p. 58) conclui:

Assim, constatamos as múltiplas faces do Outro: Outro absoluto, em termos de uma exterioridade absoluta, aquilo que não pode ser dito ou apreendido pela palavra; o Outro da alienação, como lugar onde o sujeito encontra sentido para si e onde se petrifica; o Outro da separação, que se refere ao limite que faz a falta de significante, fazendo desta carência a exigência de trabalho por parte do novo ser para dar sentido a si mesmo; e, por último, o Outro primordial que nada mais é que a presença real - outro - que encarna as funções de alienação e separação.

Nos casos de autismo e psicose, a presença e a consistência deste Outro primordial devem ser interrogadas.

Segundo Laznik-Penot (1998), em casos de autismo há justamente a ausência dessa relação com o Outro primordial, na medida em que o outro concreto capaz de sustentar a operação pulsional não se apresenta disponível. Sem este Outro encarnado não há imagem nenhuma em relação à qual o infans pode demandar reconhecimento, já que a libido carece de consistência capaz de recortar do corpo esta imagem de objeto de desejo. Nesse sentido, os adultos do entorno consideram a criança somente no nível da necessidade, produzindo o não-olhar muito relatado naqueles denominados de autistas. Se há, portanto, alguma demanda do Outro em relação à criança, essa se dá pelo avesso, isto é, que o lugar possível seja na condição de excluída do desejo materno.
Já no que se refere à psicose, o fundamento de sua estrutura está na relação do sujeito com o significante Nome-do-pai na condição de foracluído. Em outras palavras, encontramos a presença de uma mãetoda, isto é, que impede a operação da função paterna, operação esta que introduz os significantes capazes de funcionar como pontos de basta, que articulam as cadeias significantes necessárias à constituição e ao exercício de um sujeito. Esse processo de metáfora só consegue assegurar sua função estruturante com relação ao desenvolvimento psíquico da criança ao se desenvolver sob a base do recalque originário do significante do desejo da mãe. Quando o recalque originário não se dá, todo o processo de metáfora do Nome-do-pai se compromete, pois a abolição deste significante-significante Nome-do-pai-pode especificar a indução dos processos psicóticos, ou seja, quando se rejeita o significante do Nome-do-pai para fora do registro do simbólico, fracassa a metáfora paterna, e essa falha na operação de castração conferiria à psicose sua condição essencial.

Fazer da forclusão a lógica sobre a qual se articula a relação do sujeito com a linguagem é essencialmente diferente de estabelecer uma relação com o significante a partir da exclusão. Sobre essa questão, Jerusalinsky (1993, p. 63-64) faz considerações importantes. Para ele, no caso da forclusão se produz uma inscrição de sujeito, mas que exige, para se manter, sua repetição no Real. Já no caso da exclusão, ali onde deveria haver uma inscrição, encontramos a presença do vazio, o encontro com o Real.

A criança psicótica recebe a demanda do Outro numa posição em que a inscrição produzida exige, para se manter, sua repetição no Real. A diferença com o autismo é que a ausência de uma inscrição coloca a criança, a respeito da demanda do Outro, a receber essa demanda na posição de repetição da exclusão. A diferença entre o autista e o psicótico se exprime então, em que, se para o psicótico cada palavra carrega seu próprio e definitivo sentido, para o autista cada palavra carrega seu próprio apagamento.

Assim sendo, a consistência dada ao Outro pela agente materno resulta diferente numa estrutura e na outra. No caso da psicose o Outro primordial insiste em manter-se na condição de Outro da 
alienação, retendo sua cria em seu ser na qualidade de falo. Já no autismo, a presença do outro materno não garante a consistência do Outro primordial, na medida em que o filho não comparece sob a égide de objeto de desejo, estando excluído deste circuito. Com a espirituosidade que lhe é característica, esse mesmo autor situa a mãe do autista como uma 'turista do desejo' e a mãe do psicótico como uma 'profissional do desejo'. Ou seja, se para uma nada escapa ao seu olhar, transformando-se numa mãe workaholic, 24 horas, para a outra, o objeto ficará fora do seu olhar, tal como um turista que "se fotografará sempre de costas ao objeto que foi ver" (Jerusalinsky, 1993, p. 65).

Qualquer que seja a proposta de trabalho com essas crianças, institucional ou clínica, é fundamental que se observe então o lugar que este 'terapeuta' ocupará no tratamento, para que não se corra o risco de reatualizar na transferência o lugar que essa criança tem no seu encontro com seus Outros parentais. Isso implica que aquele que vier na condição de Outro só esteja aí enquanto barrado, capaz de suportar sua própria incompletude. Marie Christine Laznik-Penot (1996) afirma que nessa clínica o analista deve se apresentar como ser desejante, como um outro a quem algo falta e, assim, castrado em seu desejo onipotente.

O paciente psicótico organiza na transferência um lugar para o terapeuta em que ele está interpelando a função paterna no real, isto é, a transferência é real. Por isso, a transferência na psicose é diferente da neurose: não há suposição do saber no outro, antes supõe um gozo, não há um outro, ele fala a si mesmo por intermédio dos outros. Daío cuidado clínico de que pelo menos o analista possa interpelar seu paciente na condição de sujeito, introduzindo no dispositivo clínico algo em relação à falta. Kupfer (2000, p. 62) complementa: "Em decorrência de sua estrutura, o psicótico se coloca diante da demanda do Outro como objeto e se dirige a um analista que ele coloca em posição de sujeito.”

Já se destacou aqui como o programa de inclusão social, dependendo da sua interpretação, poderá ser nocivo à criança excluída, uma vez que a escola encarna o Outro. Desse modo, a questão que agora se destaca é: o que seria então uma instituição escolar adequada para essas crianças. Antecipamos que todo espaço em que se pretenda acolher a psicose e o autismo deve se fundamentar nessa falha citada anteriormente. Um analista, ele tem que tolerar o fracasso. Uma instituição, ela tem que tolerar o fracasso. Surge assim a importância de reformular certos conceitos arraigados no ideal político-pedagógico, para que a instituição de ensino regular possa receber essas crianças.

\section{De que modo a educação inclusiva poderá ser terapêutica?}

Ao se discutir a inserção de crianças com DGD (distúrbios globais do desenvolvimento ${ }^{1}$ ) na escola devemos levar em conta alguns aspectos fundamentais que Alfredo Jerusalinsky ${ }^{2}$ considera:

a) a questão do diagnóstico na infância, que, em sua grande maioria, não está definido. Basear-se nesse aspecto para privar a criança do convívio e da inserção na escola se torna injustificável;

b) as condições de aprendizagem, apesarde limitadas, existem, pois nestas crianças há a possibilidade de surgimento de curiosidades parciais;

c) do ponto de vista individual, a criança pequena, por causa da idade, não tem suficiência simbólica, atenuando o processo de estigmatização;

d) o efeito terapêutico causado pela inserção dessas crianças na escola pode ser entendido a partir do individuo e da ordem social. Uma vez que somente o significante escola já traz em si uma série de significações. Jerusalinsky (1997, p. 91) aponta que a "escola é um lugar de entrar e sair, é um lugar de trânsito",

\footnotetext{
1 A classificação do CID-10 é a oficialmente adotada no Brasil desde 1996. Ela considera como distúrbios globais do desenvolvimento: grupo de transtornos caracterizados por alterações qualitativas das interações sociais recíprocas e modalidades de comunicação e por um repertório de interesses e atividades restrito, estereotipado e repetitivo. Estas anomalias qualitativas constituem uma característica global do funcionamento do sujeito, em todas as ocasiões.

2 Palestra proferida em 17 de junho de 1996, no Instituto de Psicologia da Universidade de São Paulo.
} 
sem contar que na representação social a escola é considerada uma instituição normal da sociedade, na qual circula a normalidade social.

Portanto, quem frequenta a escola se sente mais reconhecido socialmente do que aquele que não frequenta. Não é à toa que adolescentes psicóticos têm o interesse de ir à escola porque seus irmãos a frequentam, funcionando para eles como signo de reconhecimento, já que são capazes de circular, de certa maneira, pela norma social. Isso, por si só, produz um efeito terapêutico, porque o discurso social cura o horror à psicose e seus preconceitos - sem contar que para o tratamento da psicose é necessário ter como norte o estabelecimento do laço social. A escola poderá produzir uma função de enlace, uma aproximação do termo "efeitos da circulação social". Kupfer e Petri (1997, p. 114) compreendem que o "trabalho analítico pode restabelecer algo do laço social e a escola, ou a circulação social que ela acarreta, reforça esse pouco do laço pondo-o em ato".

Petri (2003) complementa ao dizer que a educação se transmite tanto pelo saber quanto pelo conhecimento, sendo que este último está relacionado ao conhecimento socialmente compartilhado, transmitido de geração em geração, de modo consciente. Já o saber, de ordem inconsciente, relacionado ao desejo inconsciente, é transmitido na forma de valores e ideais. Os ideais podem ser simbólicos ou imaginários: o segundo representa a tentativa de complementação narcísica, sem espaço para a reedição do mandato; já os ideais simbólicos têm como efeito a precipitação do desejo, representados pelos ideais de eu. Este último teria a vertente de "uma filiação simbólica, efeito de uma produção de um lugar na história para um sujeito, em virtude da transmissão de marcas simbólicas advindas do passado. Educação como a possibilidade da criança vir no futuro a usufruir como um adulto do desejo que nos humaniza" (Petri, 2003, p. 29).

Isso quer dizer que, para que essa circulação se concretize, é necessário que o professor se diferencie de uma mera função pedagógica para um possível enlace, pois necessita de alguém que estabeleça um lugar simbólico, permitindo uma transmissão da cultura e não se apresente como mero guia, mas como alguém que faz parte da ordem social. O educador deve ter em mente que há um saber inconsciente, e que nele há ideais que o compõem, ideais simbólicos que vejam nessa criança um sujeito, que consiga pressupor e apostar nesse sujeito. Em outras palavras, a escola deve considerar o singular laço com o Outro que se configura no autismo e na psicose, posicionando-se como agente de discurso.

Aposta-se, com a inclusão, no poder subjetivante dos diferentes discursos que são postos em circulação, no interior do campo social, com o intuito de assegurar, sustentar ou modelar lugares sociais para as crianças, levando em conta que, neste sentido, o discurso (ou discursos) em torno do escolar é particularmente poderoso. Uma designação de lugar social é especialmente importante para as crianças que enfrentam dificuldades no estabelecimento do laço social, como é o caso das crianças psicóticas ou com transtornos graves (Kupfer \& Petri 1997, p. 115).

A circulação social diz respeito às variadas esferas da vida social, incluindo a integração da família também, pois o processo de escolarização dessas crianças encontra-se intrinsecamente ligado às significações que seus pais podem conferir-lhe sendo que a criança sofrerá diretamente os efeitos de tais significações, nos lembra Rogério Lerner (1997). Ao dizer que seu filho está na escola, a escolarização pode promover uma sustentação imaginária para os pais nessa inserção social; algum representante da ordem social também pode realizar um trabalho de escuta com os pais, "para que se instale, no lugar da certeza, uma interrogação no que se refere à interpretação que eles dão aos sintomas dos filhos" (Oliveira, 1996, p. 67). A relevância dessa escuta estaria em produzir uma virada na posição dessa criança na estrutura familiar, possibilitando um deslocamento da posição de objeto para significante.

Sem contar que o trabalho com a criança com DGD pede o reposicionamento da professora diante de seu fazer, pois ao verificar o fracasso de suas teorias pedagógicas, ela tem que estar aberta para interrogar sua prática e partir em busca de novos referenciais teóricos.

Bastos (2007, p. 46-47) complementa ao afirmar que os educadores devem estar preparados para receber esses novos alunos, tanto em conhecimento a respeito do programa de inclusão e dessa criança, quanto psiquicamente, pois muitos professores que não podem e não sabem abordar a inclusão 
acabam por pedir afastamento, licença médica, por estarem com a saúde mental debilitada.

Por outro lado, continua a autora, não podemos esquecer os efeitos da inclusão nas crianças que já frequentam a escola regular, porque estar diante do "diferente" pode produzir dois efeitos: ser uma experiência rica e produtiva ou ter efeitos negativos. As crianças neuróticas, dentro do normal, estão em um momento delicado de suas vidas, por estarem numa idade de elaborações primordiais situada num semelhante e, com a possibilidade de se encontrarem com outras crianças estranhas e destoantes da própria imagem, poderem colocar em questão pontos de identificação imaginária, de especularização com o outro.

Outro ponto que Calligaris (1989) ressalta é o perigo da inclusão funcionar como injunção fálica diante da estruturação psicótica, porque a escola pode exigir da criança algo que tem por referência a função paterna. "Nesses casos, da criança diante de um encaminhamento psicótico, corre-se o risco da instância pedagógica operar para esta criança uma injunção permanente que instale a crise, uma vez que essa referência à função paterna está em questão nesta estruturação" (1989, p. 49). Em outras palavras, é imprescindível que as metáforas maternas e paternas tenham elasticidade e estabilidade, sendo necessário por parte da equipe que acompanha essas crianças constante estudo e a permanente reflexão acerca dos efeitos dessa convivência para cada uma delas.

Levando em consideração que tanto na psicose quanto no autismo o Outro é intrusivo, encontra-se uma linha de ação de orientação psicanalítica que visa ao coletivo, fazendo da instituição um lugar de tratamento não só da criança, mas de si mesma. Parece ser nessa lógica de raciocínio que Alfredo Zenoni (1991, p. 101-113) propõe o Tratamento do Outro por meio da organização e ajuste constante do agenciamento simbólico efetuado pela escola com a finalidade de tornar possível uma ação do coletivo. Se a criança se confronta com um excesso de Outro, que se apodera sem lei do ser do infans e impõe a este um sofrimento, invadindo o sujeito com um gozo que transborda, o tratamento do Outro implicaria tratar este gozo, utilizando uma palavra dirigida a este Outro do sujeito, cuja consequência será o apaziguamento do seu gozo, na medida em que o barra.

A importância disso reside em explorar certas possibilidades, particularmente a de colocar no lugar outra Alteridade que seja alternativa ao Outro primordial do sujeito. Porém, além da simples mudança do contexto simbólico, "é todo o funcionamento do novo lugar de residência que, desde então, será atravessado pela questão das conseqüências que colocam sobre o plano do tratamento a hipótese psicanalítica sobre a psicose" (Zenoni, 1991, p. 101-113).

"Tratar o Outro é também separá-lo", nos orienta Kupfer, Faria e Keiko (2007). Operar um distanciamento entre a criança e seu Outro, uma vez que para o psicótico o outro semelhante é igual ao Outro. "Fazer isso implica tratar tudo o que é exterior à criança (sem que isso seja confundido com o ambiente familiar), ou tudo o que não faz referência direta a ela, pois isso pode ser-lhe extremamente persecutório". Alguns dos exemplos desse tratamento do Outro consiste na exclusão de ações verbais interpretativas do comportamento ou dos ditos da criança com DGD, pois isso reproduzirá um Outro do saber, persecutório, que tudo sabe; adiar o ponto de encontro com o enigma do Outro.

Todas essas ações, de acordo com Zenoni (1991, p. 101), têm a finalidade de

produzir uma distância entre seu ser de vivente, como coisa do Outro, e uma imagem, uma identificação; esboço de um outro Outro, como ideal do eu, que suporta o golpe face ao Outro persecutório, ao Outro enigmático que impõe ao sujeito ser a resposta viva a isto.

Para que se possa realizar este tratamento do Outro com o objetivo de pacificar o sujeito, colocando ordem no Outro, toda a equipe, composta por diferentes áreas, deve ser parceira na construção clínica. O objetivo é assegurar para o sujeito uma presença regular, que dá atenção ao detalhe, e que é dócil à invenção do sujeito, pois cada profissional contribui para tornar presente uma figura do Outro que permita ao sujeito encontrar para si um lugar na instituição, sem que haja passagem ao ato, tornando este Outro regulado.

Assim, adia-se o encontro da criança com o Outro para que, em um segundo momento, ela tenha condições de inventar um aparelhamento, uma nova língua e um novo engajamento psicótico no laço social. Quando esse 
encontro é adiado, cria-se uma alteridade possível para o sujeito. Essa primeira intervenção na direção de apaziguar o Outro é preliminar naquilo que acolhe, mas já é tratamento na possibilidade que traz ao sujeito para inventar qual será o próximo passo em direção à elaboração de uma estabilização. Essa estabilização poderá ocorrer com a invenção de uma metáfora não paterna; com a introdução de um menos nessa estrutura; com a criação de um saber original; ou com uma elaboração delirante sobre a sexualidade. A instituição poderá, então, testemunhar esse percurso, ao armá-lo e sustentá-lo na "prática entre vários" (Kupfer, Faria \& Keiko, 2007).

\section{Conclusão}

É por meio dessa reinvenção pacificada de um outro Outro que a criança poderá fazer laço com os outros, à sua maneira e com as oportunidades que lhe surgirão. Kupfer (1997) nos lembra que a luta política pela inclusão da criança na escola é direito de todo cidadão, propondo que se tire o máximo de proveito do potencial terapêutico presente em todo e qualquer ato educativo voltado para um sujeito, e não no adestramento de crianças, no sentido de aliená-las das práticas pedagógicas. Toda instituição de ensino deve se interrogar sobre o objetivo do trabalho ofertado a essas crianças, e isto inclui o desejo do educador em acolher este aluno. Se elas não aprenderão como as outras, para que ir a uma escola regular? A escola em nossos dias ainda permanece como um território que delimita a criança num tempo de infância, em que, a despeito de todas as diferenças, ali elas são iguais, na medida em que o significante 'aluno' representa a todos. Enfim, trata-se de questionar se essas crianças têm estrutura suficiente para usufruir daquilo que o convívio social pode lhes proporcionar enquanto abertura a novos laços sociais e se a escola reconhece a criança menos sob a ótica de suas capacidades cognitivas do que na sua condição de sujeito do desejo. A inclusão só acontece realmente quando o aluno dá certo com a escola como um todo, não somente com o educador. Que a escola, ao acolher alunos autistas e psicóticos, inclua a subjetividade de todos envolvidos nesse processo. Desafio permanente neste trabalho.

\section{Agradecimentos}

Este trabalho foi escrito no ano mais difícil da minha vida. Agradeço à minha família pelo apoio, pela força e principalmente pelo amor. Sem vocês, eu nada seria.

Ao Thiago, eterno companheiro dos meus primeiros passos acadêmicos.

\section{Referências}

Alberti, S., \& Miranda, E. R. (2002). A debilidade mental na estrutura. Psyché, 6(9), 33-53.

Aragão, L. T., \& Ramirez, H. H. (2004). Sobre a metáfora paterna e a foraclusão do nome-do-pai: uma introdução. Psicologia USP, 2(3). Recuperado em 7 maio 2008, em http:/ / scielo.bvs-psi.org.br/scielo.php

Bastos, M. B. (2001). Impasses vividos pela professora na inclusão escolar. Estilos da clínica: Revista sobre a infância com problemas, 6(11), 47-55.

Calligaris, C. Introdução a uma clinica diferencial das psicoses. Porto Alegre: Artes Médicas, 1989.

Colli, F. (1997). Começando uma travessia pela Ponte. Estilos da clínica: Revista sobre a Infância com Problemas, 2(2), 139-144.

Dayrell, M. A. A. (2008). Sobre a direção do tratamento. Psicologia USP, 19(54). Recuperado em 29 set. 2008, em http: www.scielo.br

Freud, S. (2006). Análise terminável e interminável. In S. Freud Moisés e o Monoteísmo, esboço de psicanálise e outros trabalhos (pp. 231-246). Rio de Janeiro: Imago. (Original publicado em 1937).

Jerusalinsky, A. (1993). Psicose e autismo na infância: Uma questão de linguagem. Boletim da Associação Psicanalítica de Porto Alegre, 4(9), 63-70.

Jerusalinsky, A. (1997). A escolarização de crianças psicóticas. Estilos da Clínica: Revista sobre a Infância com Problemas, 2(2), 72-95.

Kupfer, M. C. (1997). Educação terapêutica: O que a psicanálise pode pedir à educação. Estilos da Clínica: Revista sobre a Infância com Problemas, 2(2), p. 53-61.

Kupfer, M. C. (2000). Educação para o futuro: Psicanálise e educação. São Paulo: Escuta. 
Kupfer, M. C., \& Petri, R. (2000). Por que ensinar a quem não aprende? Estilos da Clínica: Revista sobre a Infância com Problemas, 5(9), 109-117.

Kupfer, M. C., Faria, C., \& Keiko, C. (2007). O tratamento institucional do outro na psicose infantil e no autismo. Arquivos Brasileiros de Psicologia, 59(2). Recuperado em 1 set. 2008, em http://146.164.3.26/seer/lab19/ojs2/index.php/ ojs $2 /$ article/view/144/120

Lacan, J. (1993). O seminário livro 11: Os quatro conceitos fundamentais de psicanálise. Rio de Janeiro: Jorge Zahar. (Original publicado em 1964).

Lacet, C. (2004). Da foraclusão do Nome-do-pai à foraclusão generalizada: Considerações sobre a teoria das psicoses em Lacan. Psicologia USP, 15(12). Recuperado em 12 out. 2007, em http:// www. scielo.br

Laznik-Penot, M-C. (1998). Do fracasso da instauração da imagem do corpo ao fracasso da instauração do circuito pulsional: Quando a alienação faz falta. In M-C. Laznik-Penot. O que a clínica do autismo pode ensinar aos psicanalistas (pp.31-48). Salvador: Álgama.

Lerner, R. (1997). Escolarização de crianças portadoras de distúrbios globais do desenvolvimento: Dados e reflexões a respeito dos aspectos envolvidos. Estilos da Clínica: Revista sobre a Infância com Problemas, 2(2), 62-71.

Mariotto, R. M. M. (2007). Cuidar, educar e prevenir: As funções da creche no desenvolvimento e na subjetivação de bebês. Tese de Doutorado, Instituto de Psicologia da Universidade de São Paulo, São Paulo.

Miller,J. A. (1998). A criança entre a mulher e a mãe. Opção Lacaniana: Revista Brasileira Internacional de Psicanálise, 21(4), 7-12.

Petri, R. (2003). Psicanálise e educação no tratamento da psicose infantil: Quatro experiências institucionais. São Paulo: Annablume; FAPESP.

Secretaria de Educação Especial. Conceitos da educação especial. Recuperado em 14 jul. 2009, em http:// portal.mec.gov.br/index.php?option=com_content \&view $=$ article\&id $=288 \&$ Itemid $=355$.
Souza, R. M; Angelis, W, Veras, V. (2000). Entre o dizer e o fazer: $\mathrm{O}$ discurso oficial sobre a inclusão e suas contradições Estilos da Clínica: Revista sobre a Infância com Problemas, 5(9), 82-95.

Zenoni, A. (1991). "Traitement" de l'autre. Révue Préliminaire, 110(3), 101-113.

Recebido: 27/07/2009

Received: 07/27/2009

Aprovado: 26/10/2009

Approved: 10/26/2009 